\title{
Evaluasi Prediksi Nilai Higher Heating Value (HHV) Biomassa Berdasarkan Analisis Ultimate
}

\section{Evaluation of Prediction Higher Heating Value (HHV) of Biomass-Based on Ultimate Analysis}

\author{
Made Dirgantara $^{1 *}$, Novi Kristian ${ }^{1}$, Karelius $^{2}$ \\ ${ }^{1}$ Program Studi Fisika, Fakultas Matematika dan Ilmu Pengetahuan Alam, Universitas Palangka Raya, Kalimantan Tengah \\ ${ }^{2}$ Program Studi Kimia, Fakultas Matematika dan Ilmu Pengetahuan Alam, Universitas Palangka Raya, Kalimantan Tengah \\ *Alamat email: dirgantaramade@mipa.upr.ac.id
}

\begin{abstract}
Abstrak - Biomassa merupakan energi terbarukan yang sangat penting, dimana keberadaannya dapat menggantikan bahan bakar fosil baik padat maupun cair. Sebagai bahan bakar tentu perlu adanya analisis-analisis untuk mengetahui karakteristik dan kualitas biomassa sehingga kita dapat mengklasifikasikan biomassa yang potensial digunakan sebagai bahan bakar. Nilai kalori atau higher heating value (HHV) merupakan sifat terpenting dari suatu bahan bakar. Pada umumnya pengukuran nilai kalori menggunakan bomb calorimeter, akan tetapi pengukuran ini memerlukan waktu dan biaya sehingga tidak efektif jika yang dianalisis dalam jumlah banyak. Dalam makalah ini akan dibahas persamaan untuk memprediksi nilai HHV biomassa berdasarkan analisis ultimate yang di dapatkan dari penelitian sebelumnya. Empat prediksi nilai HHV menggunakan 15 data komposisi kimia biomassa dari penelitian sebelumnya kemudian dibandingkan berdasarkan ketepatan untuk mendapatkan prediksi terbaik. Persamaan P1 dan P4 terbaik dalam memprediksi nilai HHV berdasarkan data analisis ultimate, dimana masing-masing memprediksi terbaik di lima biomassa. Berdasarkan sumber biomassa, persamaan P1 baik dalam memprediksi hasil perkebunan dan pertanian yang berupa serabut/serat tinggi dengan kadar karbon dan oksigen yang tinggi dan tidak memiliki sulfur. P4 baik dalam memprediksi biomassa hasil sampingan kehutanan dengan karakter tinggi kadar karbon dan oksigen, rendah hydrogen dan oksigen serta memiliki sulfur.
\end{abstract}

Kata kunci: analisis ultimate, bahan bakar, biomassa, higher heating value

\begin{abstract}
Biomass is a very important renewable energy, where its existence can replace fossil fuels, both solid and liquid. As a fuel, there should be analyzes to determine the characteristics and quality of biomass so that we can classify biomass that is potentially used as fuel. The calorific value or higher heating value (HHV) is the most important property of fuel. In general, measuring the caloric value using a bomb calorimeter, but this measurement requires time and cost, so it is not effective if the amount analyzed a lot. This paper will discuss the prediction of the value of HHV biomass based on the ultimate analysis obtained from previous studies. Four predictions of HHV value using 15 chemical composition data from previous studies were then compared with accuracy to get the best prediction. Equation P1 and P4 is the best for predicting HHV values based on ultimate analysis data, where each predicts the best in five biomasses. Based on biomass sources, the P1 equation is useful for predicting plantation and agricultural output in the form of high fiber with high carbon and oxygen content and does not have sulfur. P4 helps predict forestry by-product biomass with the character of high carbon and oxygen content, low in hydrogen and oxygen, and has sulfur.
\end{abstract}

Keywords: biomass, fuel, higher heating value, ultimate analysis

(C) 2019 Jurnal Jejaring Matematika dan Sains. This work is licensed under a $\underline{\text { CC BY-NC 4.0 }}$

Sejarah Artikel

Diterima : 20 November 2019

Disetujui : 26 Desember 2019 


\section{PENDAHULUAN}

Pencarian sumber energi alternatif terbaharukan, ramah lingkungan dan ekonomis terus digalakkan untuk menjaga kelestarian lingkungan serta menurunkan emisi $\mathrm{CO}_{2}$ ke atmosfer. Salah satu sumber energi terbaharukan tersebut adalah biomassa yang didefinisikan sebagai produk organik dari pertanian dan kehutanan hasil proses fotosintesis [1]. Biomassa merupakan bahan bakar yang dapat digunakan langsung atau diolah terlebih dahulu menjadi bahan bakar padat, cair atau gas melalui proses tertentu untuk meningkatkan kualitasnya sebagai bahan bakar [2]-[4]. Proses termokimia biomassa untuk menghasilkan bahan bakar padat saat ini tengah banyak dilakukan khususnya untuk substitusi batubara di berbagai industri [5], [6].

Indonesia merupakan negara yang memiliki potensi biomassa yang sangat tinggi [1], akan tetapi masih belum dimanfaatkan secara maksimal. Sebagai bahan bakar khususnya bahan bakar padat nilai kalori merupakan faktor penting selain karakteristik pendukung seperti analisis ultimate dan proksimat [7], [8]. Nilai kalori biomassa secara umum terbagi dua yakni Higher Heating Value (HHV) yang didefinisan sebagai panas yang dilepaskan selama proses pemakaran dan Low Heat Value (LHV) yang didefinisan sebagai energy yang diperlukan untuk menguapkan air [9]. HHV sebagai parameter energy yang terkandung dalam biomassa merupakan faktor penting dalam proses pembakaran [10]. Dalam pengembangan biomassa sebagai bahan bakar tentu perlu dilakukan banyak uji baik itu uji utama ataupun uji pendukung dan hal ini tentu memerlukan banyak biaya sehingga perlu adanya suatu prediksi suatu parameter dari parameter lainnya yang terkait. Penggunaan data analisis ultimate telah banyak digunakan untuk memprediksi nilai HHV [9][12] akan tetapi evaluasi eror prediksi HHV terbaru belum dilakukan.

Empat persamaan untuk mempredisksi nilai HHV dari data analisis ultimate dievaluasi ketepatannya dengan 15 data biomassa yang memiliki data ultimat dan HHV. Keseluruhan data tersebut diambil dari berbagai sumber jurnal ilmiah. Ketepatan prediksi dievaluasi dengan estimasi nilai eror yakni average absolute eror (AAE), average bias eror (ABE) dan mean absolute eror (MAE) sehingga di dapat prediksi HHV terbaik berdasarkan data ultimate.

\section{METODE PENELITIAN}

\section{A. Pengumpulan Data}

Pengambilan data dan persamaan estimasi dilakukan dengan metode studi literatur. Data yang diambil berasal dari jurnal penelitian sebelumnya yang bersumber dari google scholar dan sciendirec. Kata kunci yang digunakan untuk penelusuran tersebut adalah estimation hhv, estimation hhv biomass, prediction hhv, prediction hhv biomass, hhv ultimate, torrefaction biomass, ultimate biomass dan ultimat biomassa. Dari hasil penelusuran tersebut kemudian dipilih empat persamaan terbaru dan terbaik yang nantinya akan dievaluasi dengan 15 data ultimat biomassa.

B. Persamaan Prediksi Nilai Kalor Dari DaTa Ultimate

Adapun persamaan prediksi nilai kalor (HHV) dalam makalaah ini adalah sebagai berikut.

Tabel 1. Persamaa untuk prediksi nilai kalor

\begin{tabular}{|c|c|c|}
\hline Kode & Persamaan HHV & Ref. \\
\hline $\mathrm{P} 1$ & $\begin{aligned} \mathrm{HHV} & =3.918+0.276 \times \mathrm{C}+0.016 \times \mathrm{H} \\
& +0.020 \times \mathrm{O}+0.245 \times \mathrm{N}\end{aligned}$ & [13] \\
\hline $\mathrm{P} 2$ & $\begin{array}{c}\mathrm{HHV}=-4.437+0.879 \times \mathrm{C}+0.278 \times \\
\mathrm{H}-0.144 \times \mathrm{O}-0.195 \times \mathrm{N}-0.007 \times \\
\mathrm{C}^{2}-0.015 \times \mathrm{H}^{2-} 0.001 \times \mathrm{O}^{2}+0.057 \times \\
\mathrm{N}^{2}\end{array}$ & [14] \\
\hline P3 & $\begin{array}{c}\mathrm{HHV}=-4.914+0.2611 \mathrm{~N}+0.4114 \\
\mathrm{C}+0.6114 \mathrm{H}+0.3888 \mathrm{~S}+0.02097 \mathrm{O} \\
\mathrm{N}^{2}\end{array}$ & [14] \\
\hline $\mathrm{P} 4$ & $\begin{array}{c}H H V=-4,6246+0,2732 N+0,4120 \\
C+0,5992 H+0,01841 O\end{array}$ & [15] \\
\hline
\end{tabular}

\section{Estimasi Nilai Eror}

Tiga estimasi eror yang digunakan yakni [16] [17] :

$$
\begin{aligned}
\mathrm{MAE} & =\frac{1}{n} \sum_{i=1}^{n}\left|H H V_{(p)}-H H V_{(e)}\right| \\
\mathrm{AAE} & =\frac{1}{n} \sum_{i=1}^{n}\left|\frac{H H V_{(p)}-H H V_{(e)}}{H H V_{(e)}}\right| \\
\mathrm{ABE} & =\frac{1}{n} \sum_{i=1}^{n}\left(\frac{H H V_{(p)}-H H V_{(e)}}{H H V_{(e)}}\right)
\end{aligned}
$$

Keterangan :

$\mathrm{HHV}_{(\mathrm{p})}=\mathrm{HHV}$ prediksi

$\mathrm{HHV}_{(\mathrm{e})}=\mathrm{HHV}$ eksperimen 


\section{HASIL DAN PEMBAHASAN}

Data analisis ultimate terdiri dari karbon $(\mathrm{C})$, oksigen $(\mathrm{O})$, hidrogen $(\mathrm{H})$ dan nitrogen $(\mathrm{N})$ dimana beberapa biomassa memiliki sulfur (S) yang merupakan zat berbahaya yang biasa ada di batubara. Data analisis ultimate dan HHV yang diperoleh secara eksperimen melalui literature disajikan pada Tabel 2. Biomassa tersebut terdiri dari hasil sampingan perkebunan dan kehutanan serta limbah makanan perkotaan. Berdasarkan data tersebut kemudian dilakukan prediksi menggunakan persaman P1, P2, P3 dan P4 ke masing-masing biomassa dan estimasi nilai eror yang ditunjukan pada Tabel 3. MAE dan AAE menunjukan eror dari prediksi dimana semakin kecil nilai MAE dan AAE maka semakin baik prediksi yang dihasilkan, sementara ABE menunjukan apakah bias ke (+) artinya lebih besar atau ke (-) artinya prediksi lebih kecil [10], [12], [13], [18].

Tabel 2. Data analisis ultimate dan HHV eksperimen

\begin{tabular}{|c|c|c|c|c|c|c|c|c|}
\hline No & Biomassa & $\mathbf{C}$ & $\mathbf{O}$ & $\mathbf{H}$ & $\mathbf{N}$ & $\mathbf{S}$ & HHV & Referensi \\
\hline 1. & Sabut kelapa & 47.6 & 45.6 & 5.7 & 0.2 & 0.00 & 14.67 & [19] \\
\hline 2. & Kayu manga & 46.2 & 44.4 & 6.1 & 0.28 & 0.00 & 19.17 & [19] \\
\hline 3. & Limbah teh & 45.04 & 40.21 & 6.07 & 3.48 & 0.50 & 19.87 & [20] \\
\hline 4. & Limbah makanan sisa & 47,39 & 3.32 & 6.90 & 3.32 & 0.27 & 17.45 & [16] \\
\hline 5. & Tandan buah sawit & 44.66 & 45.4 & 7.12 & 0.38 & 0.00 & 14,231 & [21] \\
\hline 6. & Pelet kayu & 45.07 & 0.18 & 7.12 & 0.00 & 0.00 & 14,272 & [21] \\
\hline 7. & Sekam padi & 37.10 & 0.14 & 5.76 & 0.00 & 0.00 & 13,954 & [21] \\
\hline 8. & Biji marula & 47.38 & 44.46 & 6.33 & 1.46 & 0.37 & 20.40 & [22] \\
\hline 9. & Kayu gusi biru & 50.13 & 43.16 & 5.96 & 0.53 & 0.22 & 19.74 & [22] \\
\hline 10. & Cangkang inti sawit & 47.67 & 46.42 & 47.67 & 0.39 & 0.00 & 19.00 & [23] \\
\hline 11. & Cabang pohon cemara & 50.96 & 42.06 & 6.18 & 0.12 & 0.00 & 16.42 & [24] \\
\hline 12. & Jerami gandum & 45.5 & 47.9 & 47.9 & 1.0 & 0.00 & 16.5 & [25] \\
\hline 13. & Limbah makanan & 45.33 & 45.75 & 6.99 & 1.29 & 0.20 & 18.08 & [26] \\
\hline 14. & Serpihan kayu pinus & 49.73 & 43.28 & 6.17 & 0.14 & 0.00 & 20.42 & {$[27]$} \\
\hline 15. & Kulit pinus & 54.33 & 36.59 & 6.96 & 0.23 & 0.00 & 21.48 & [27] \\
\hline
\end{tabular}

Empat pesamaan yang dievaluasi memiliki karakteristik yang berdeda, dimana P1 memprediksi terbaik di 5 jenis biomassa, $\mathrm{P} 2$ di satu jenis biomassa, $\mathrm{P} 3$ di 5 jenis biomassa dan P4 di 4 biomassa. Persamaan P1 terbaik dalam memprediksi nilai HHV untuk sabut kelapa, tandan buah sawit, pelet kayu, cangkang sawit dan jerami gandum dimana nilai MAE dan AAE lebih kecil dari $1 \%$ dengan nilai $\mathrm{ABE}(-)$. Berdasarkan analisis ultimate biomassa tersebut memiliki kesamaan dimana memiliki kadar karbon dan oksigen yang tinggi dan tidak memiliki sulfur. Berdasarkan sumber biomassa, persamaan P1 baik dalam memprediksi hasil perkebunan dan pertanian yang berupa serabut/serat tinggi. Persamaan P2 terbaik dalam memprediksi cabang pohon cemara dengan AAE dibawah $1 \%$, selain itu P2 juga memiliki nilai MAE dan AAE yang baik untuk memprediksi sabut kelapa. Komposisi cabang pohon cemara berdasarkan analisis ultimate memiliki kadar karbon dan oksigen yang tinggi dengan rendah hidrogen dan nitrogen. Persamaan P3 terbaik dalam memprediksi limbah makanan, sekam padi, serpihan kayu pinus dan kayu gusi biru. Dari semua biomassa tersebut P3 terbaik untuk memprediksi sekam padi dimana 
berdasarkan analisis ultimate memiliki karakter tinggi karbon rendah oksigen dan minim nitrogen serta sulfur. Persamaan P4 terbaik dalam memprediksi kayu manga, limbah teh, biji marula dan kulit pinus dimana nilai eror terkecil untuk memprediksi HHV biji marula dengan karakter tinggi kadar karbon dan oksigen, rendah hydrogen dan oksigen serta memiliki sulfur.

Tabel 3. Predikisi dan estimasi nilai eror

\begin{tabular}{|c|c|c|c|c|c|c|}
\hline Biomassa & $\begin{array}{c}\text { HHV } \\
\text { Eksperimen } \\
(\mathrm{MJ} / \mathbf{k g})\end{array}$ & $\begin{array}{c}\text { Kode } \\
\text { Prediksi }\end{array}$ & $\begin{array}{c}\text { HHV } \\
\text { Prediksi } \\
\text { (MJ/Kg) }\end{array}$ & MAE & $\mathbf{A A E}$ & ABE \\
\hline \multirow{4}{*}{ Sabut kelapa } & \multirow{4}{*}{14.67} & $\mathrm{P} 1$ & 14.1898 & 0.032013333 & 0.002182231 & -0.002182231 \\
\hline & & $\mathrm{P} 2$ & 13.95785 & 0.047476667 & 0.00323631 & -0.003236310 \\
\hline & & P3 & 19.16207 & 0.299471333 & 0.02041386 & 0.020413860 \\
\hline & & P4 & 19.29618 & 0.308412000 & 0.021023313 & 0.021023313 \\
\hline \multirow{4}{*}{ Kayu manga } & \multirow{4}{*}{19.17} & $\mathrm{P} 1$ & 13.8054 & 0.357640000 & 0.018656234 & -0.018656234 \\
\hline & & $\mathrm{P} 2$ & 13.95428 & 0.347714667 & 0.018138480 & -0.018138480 \\
\hline & & P3 & 18.8264 & 0.022906667 & 0.001194923 & -0.001194923 \\
\hline & & P4 & 18.95882 & 0.014078667 & 0.000734411 & -0.000734411 \\
\hline \multirow{4}{*}{ Limbah teh } & \multirow{4}{*}{19.87} & $\mathrm{P} 1$ & 14.18496 & 0.379002667 & 0.019074115 & -0.019074115 \\
\hline & & $\mathrm{P} 2$ & 14.69234 & 0.979489333 & 0.017371783 & -0.017371783 \\
\hline & & P3 & 19.27289 & 1.284859333 & 0.002003389 & -0.002003389 \\
\hline & & $\mathrm{P} 4$ & 19.26003 & 1.284002000 & 0.002046536 & -0.002046536 \\
\hline \multirow{4}{*}{$\begin{array}{c}\text { Limbah } \\
\text { makanan }\end{array}$} & \multirow{4}{*}{17.45} & $\mathrm{P} 1$ & 14.06984 & 0.225344000 & 0.012913696 & -0.012913696 \\
\hline & & $\mathrm{P} 2$ & 22.19395 & 0.316263333 & 0.018123973 & 0.018123973 \\
\hline & & P3 & 19.84235 & 0.159490000 & 0.009139828 & 0.009139828 \\
\hline & & P4 & 20.00271 & 0.170180667 & 0.009752474 & 0.009752474 \\
\hline \multirow{4}{*}{$\begin{array}{c}\text { Tandan buah } \\
\text { sawit }\end{array}$} & \multirow{4}{*}{14.231} & $\mathrm{P} 1$ & 13.44118 & 0.052654667 & 0.003699998 & -0.003699998 \\
\hline & & $\mathrm{P} 2$ & 13.41185 & 0.894123333 & 0.003837397 & -0.003837397 \\
\hline & & P3 & 18.86355 & 1.257570000 & 0.021701684 & 0.021701684 \\
\hline & & $\mathrm{P} 4$ & 18.98125 & 1.265416667 & 0.022253063 & 0.022253063 \\
\hline \multirow{4}{*}{ Pelet kayu } & \multirow{4}{*}{14.272} & $\mathrm{P} 1$ & 12.55684 & 0.114344000 & 0.008011771 & -0.008011771 \\
\hline & & $\mathrm{P} 2$ & 22.15339 & 0.525426000 & 0.036815163 & 0.036815163 \\
\hline & & $\mathrm{P} 3$ & 17.98474 & 0.247516000 & 0.017342769 & 0.017342769 \\
\hline & & P4 & 18.21386 & 0.262790667 & 0.018413023 & 0.018413023 \\
\hline \multirow{4}{*}{ Sekam padi } & \multirow{4}{*}{13.954} & $\mathrm{P} 1$ & 10.33456 & 0.241296000 & 0.017292246 & -0.017292246 \\
\hline & & $\mathrm{P} 2$ & 19.62247 & 0.377898000 & 0.027081697 & 0.027081697 \\
\hline & & P3 & 13.87354 & 0.005364000 & 0.000384406 & -0.000384406 \\
\hline & & P4 & 14.11457 & 0.010704667 & 0.000767140 & 0.000767140 \\
\hline \multirow{4}{*}{ Biji marula } & \multirow{4}{*}{20.4} & $\mathrm{P} 1$ & 14.42506 & 0.398329333 & 0.019525948 & -0.019525948 \\
\hline & & $\mathrm{P} 2$ & 14.11255 & 0.419163333 & 0.020547222 & -0.020547222 \\
\hline & & $\mathrm{P} 3$ & 19.90568 & 0.032954667 & 0.001615425 & -0.001615425 \\
\hline & & $\mathrm{P} 4$ & 19.90628 & 0.032914667 & 0.001613464 & -0.001613464 \\
\hline \multirow{4}{*}{ Kayu gusi biru } & \multirow{4}{*}{19.74} & $\mathrm{P} 1$ & 14.92429 & 0.321047333 & 0.016263796 & -0.016263796 \\
\hline & & $\mathrm{P} 2$ & 14.99504 & 0.316330667 & 0.016024856 & -0.016024856 \\
\hline & & P3 & 20.48241 & 0.049494000 & 0.002507295 & 0.002507295 \\
\hline & & $\mathrm{P} 4$ & 20.53952 & 0.053301333 & 0.002700169 & 0.002700169 \\
\hline
\end{tabular}




\begin{tabular}{|c|c|c|c|c|c|c|}
\hline \multirow{3}{*}{$\begin{array}{c}\text { Cangkang } \\
\text { sawit }\end{array}$} & \multirow{4}{*}{19} & $\mathrm{P} 1$ & 14.94359 & 0.270427333 & 0.014233018 & -0.014233018 \\
\hline & & $\mathrm{P} 2$ & -8.18292 & 1.812194667 & 0.095378667 & -0.095378667 \\
\hline & & P3 & 44.91813 & 1.727875333 & 0.090940807 & 0.090940807 \\
\hline \multirow{5}{*}{$\begin{array}{l}\text { Cabang pohon } \\
\text { cemara }\end{array}$} & & $\mathrm{P} 4$ & 44.54044 & 1.702696000 & 0.089615579 & 0.089615579 \\
\hline & \multirow{4}{*}{16.42} & P1 & 15.03444 & 0.092370667 & 0.005625497 & -0.005625497 \\
\hline & & $\mathrm{P} 2$ & 15.47528 & 0.062981333 & 0.003835648 & -0.003835648 \\
\hline & & P3 & 20.74273 & 0.288182000 & 0.017550670 & 0.01755067 \\
\hline & & $\mathrm{P} 4$ & 20.53956 & 0.274637333 & 0.016725782 & 0.016725782 \\
\hline \multirow{4}{*}{ Jerami gandum } & \multirow{4}{*}{16.5} & $\mathrm{P} 1$ & 14.5274 & 0.131506667 & 0.007970101 & -0.007970101 \\
\hline & & $\mathrm{P} 2$ & -9.36421 & 1.724280667 & 0.104501859 & -0.104501859 \\
\hline & & P3 & 44.35632 & 1.857088000 & 0.112550788 & 0.112550788 \\
\hline & & $\mathrm{P} 4$ & 44.54044 & 1.869362667 & 0.113294707 & 0.113294707 \\
\hline \multirow{4}{*}{$\begin{array}{c}\text { Limbah } \\
\text { Makanan }\end{array}$} & \multirow{4}{*}{18.08} & P1 & 13.85397 & 0.281735333 & 0.015582706 & -0.015582706 \\
\hline & & $\mathrm{P} 2$ & 13.39697 & 0.312202000 & 0.017267810 & -0.01726781 \\
\hline & & P3 & 19.3824 & 0.086826667 & 0.004802360 & 0.00480236 \\
\hline & & $\mathrm{P} 4$ & 20.88108 & 0.186738667 & 0.010328466 & 0.010328466 \\
\hline \multirow{4}{*}{$\begin{array}{l}\text { Serpihan kayu } \\
\text { pinus }\end{array}$} & \multirow{4}{*}{20.42} & $\mathrm{P} 1$ & 14.7241 & 0.379726667 & 0.018595821 & -0.018595821 \\
\hline & & $\mathrm{P} 2$ & 14.97673 & 0.362884667 & 0.017771041 & -0.017771041 \\
\hline & & P3 & 20.2614 & 0.010573333 & 0.000517793 & -0.000517793 \\
\hline & & P4 & 20.21565 & 0.013623333 & 0.000667156 & -0.000667156 \\
\hline \multirow{4}{*}{ Kulit pinus } & \multirow{4}{*}{21.48} & $\mathrm{P} 1$ & 15.89459 & 0.372360667 & 0.017335227 & -0.017335227 \\
\hline & & $\mathrm{P} 2$ & 17.21546 & 1.147697333 & 0.013235692 & -0.013235692 \\
\hline & & $\mathrm{P} 3$ & 22.52005 & 1.501336667 & 0.003227964 & 0.003227964 \\
\hline & & $\mathrm{P} 4$ & 21.94915 & 1.463276667 & 0.001456083 & 0.001456083 \\
\hline
\end{tabular}

\section{KESIMPULAN}

Persamaan P1 dan P4 terbaik dalam memprediksi nilai HHV berdasarkan data analisis ultimate, dimana masing-masing memprediksi terbaik di lima biomassa. Berdasarkan sumber biomassa, persamaan P1 baik dalam memprediksi hasil perkebunan dan pertanian yang berupa serabut/serat tinggi dengan kadar karbon dan oksigen yang tinggi dan tidak memiliki sulfur. P4 baik dalam memprediksi biomassa hasil sampingan kehutanan dengan karakter tinggi kadar karbon dan oksigen, rendah hydrogen dan oksigen serta memiliki sulfur.

\section{REFERENSI}

[1] R. Alamsyah, N. C. Siregar, dan F. Hasanah, "Torrefaction study for energy upgrading on Indonesian biomass as low emission solid fuel," IOP Conf. Ser. Earth Environ. Sci., vol. 65, hlm. 012051, Mei 2017, doi: 10.1088/17551315/65/1/012051.

[2] K. G. Suastika, K. Karelius, M. Dirgantara, dan N. Rumbang, "Proses Torefaksi Untuk Meningkatkan Nilai Kalor Cangkang Sawit," Risal. Fis., vol. 3, no. 2, hlm. 4750, Sep 2019, doi: 10.35895/rf.v3i2.159.
[3] K. R. Arturi, S. Kucheryavskiy, dan E. G. Søgaard, "Performance of hydrothermal liquefaction (HTL) of biomass by multivariate data analysis," Fuel Process. Technol., vol. 150, hlm. 94-103, Sep 2016, doi: 10.1016/j.fuproc.2016.05.007.

[4] A. AlNouss, G. McKay, dan T. Al-Ansari, "Production of syngas via gasification using optimum blends of biomass," J. Clean. Prod., vol. 242, hlm. 118499, Jan 2020, doi: 10.1016/j.jclepro.2019.118499.

[5] B. Acharya dan A. Dutta, "Fuel property enhancement of lignocellulosic and nonlignocellulosic biomass through torrefaction," Biomass Convers. Biorefinery, vol. 6, no. 2, hlm. 139-149, Jun 2016, doi: 10.1007/s13399-015-0170-x.

[6] R. Ahmad, K. Ismail, M. A. M. Ishak, N. N. Kasim, dan C. Z. A. Abidin, "Pretreatment of palm kernel shell by torrefaction for co-gasification," dalam 4th IET Clean Energy and Technology Conference (CEAT 2016), 2016, hlm. 1-6, doi: 10.1049/cp.2016.1327. 
[7] G. D. Gillespie, C. D. Everard, C. C. Fagan, dan K. P. McDonnell, "Prediction of quality parameters of biomass pellets from proximate and ultimate analysis," Fuel, vol. 111, hlm. 771-777, Sep 2013, doi: 10.1016/j.fuel.2013.05.002.

[8] P. Sirisomboon, A. Funke, dan J. Posom, "Improvement of proximate data and calorific value assessment of bamboo through near infrared wood chips acquisition," Renew. Energy, vol. 147, hlm. 1921-1931, Mar 2020, doi: 10.1016/j.renene.2019.09.128.

[9] R. Elneel, S. Anwar, dan B. Ariwahjoedi, "Prediction of Heating Values of Oil Palm Fronds from Ultimate Analysis," J. Appl. Sci., vol. 13, no. 3, hlm. 491-496, 2013, doi: 10.3923/jas.2013.491.496.

[10] D. R. Nhuchhen dan M. T. Afzal, "HHV Predicting Correlations for Torrefied Biomass Using Proximate and Ultimate Analyses," Bioengineering, vol. 4, no. 1, Jan 2017, doi: 10.3390/bioengineering4010007.

[11] S. Hosseinpour, M. Aghbashlo, M. Tabatabaei, dan M. Mehrpooya, "Estimation of biomass higher heating value (HHV) based on the proximate analysis by using iterative neural network-adapted partial least squares (INNPLS)," Energy, vol. 138, hlm. 473-479, Nov 2017, doi: 10.1016/j.energy.2017.07.075.

[12] W. Setyawati, E. Damanhuri, P. Lestari, dan K. Dewi, "Correlation Equation to Predict HHV of Tropical Peat Based on its Ultimate Analyses," Procedia Eng., vol. 125, hlm. 298-303, Jan 2015, doi: 10.1016/j.proeng.2015.11.048.

[13] A. Dashti, A. S. Noushabadi, M. Raji, A. Razmi, S. Ceylan, dan A. H. Mohammadi, "Estimation of biomass higher heating value (HHV) based on the proximate analysis: Smart modeling and correlation," Fuel, vol. 257, no. March, hlm. 115931, 2019, doi: 10.1016/j.fuel.2019.115931.

[14] A. Özyuğuran, S. Yaman, dan S. Küçükbayrak, "Prediction of calorific value of biomass based on elemental analysis," vol. 02, no. 03, hlm. 254-260, 2018.

[15] F. P. Estimation, W. Fuels, dan R. D. Fuel, "An universal method to predict higher heating values of fuel compounds," no. July, 2016.

[16] F. R. A. Abdul Wahid, S. Saleh, dan N. A. F. Abdul Samad, "Estimation of Higher Heating Value of Torrefied Palm Oil Wastes from Proximate Analysis," Energy Procedia, vol. 138, hlm. 307-312, 2017, doi: 10.1016/j.egypro.2017.10.102.
[17] C. Y. Yin, "Prediction of higher heating values of biomass from proximate and ultimate analyses," Fuel, vol. 90, no. 3, hlm. 1128-1132, 2011, doi: 10.1016/j.fuel.2010.11.031.

[18] B.-J. Lin $d k k$., "Prediction of higher heating values (HHVs) and energy yield during torrefaction via kinetics," Energy Procedia, vol. 158, hlm. 111-116, Feb 2019, doi: 10.1016/j.egypro.2019.01.054.

[19] I. Estiati, F. B. Freire, J. T. Freire, R. Aguado, dan M. Olazar, "Fitting performance of artificial neural networks and empirical correlations to estimate higher heating values of biomass," Fuel, vol. 180, hlm. 377-383, 2016, doi: 10.1016/j.fuel.2016.04.051.

[20] A. ÖzyuğUran dan S. Yaman, "Prediction of Calorific Value of Biomass from Proximate Analysis," Energy Procedia, vol. 107, no. September 2016, hlm. 130-136, 2017, doi: 10.1016/j.egypro.2016.12.149.

[21] S. B. Nam, Y. S. Park, D. J. Kim, dan J. H. Gu, "Torrefaction Reaction Characteristic of Various Biomass Waste on Pilot Scale of Torrefaction Reaction System," Procedia Environ. Sci., vol. 35, hlm. 890-894, 2016, doi: 10.1016/j.proenv.2016.07.044.

[22] T. A. Mamvura, G. Pahla, dan E. Muzenda, "Torrefaction of waste biomass for application in energy production in South Africa," South Afr. J. Chem. Eng., vol. 25, hlm. 112, 2018, doi: 10.1016/j.sajce.2017.11.003.

[23] R. Ahmad, K. Ismail, M. A. M. Ishak, N. N. Kasim, dan C. Z. A. Abidin, "Pretreatment of palm kernel shell by torrefaction for cogasification," IET Conf. Publ., vol. 2016, no. CP688, hlm. 1-6, 2016, doi: 10.1049/cp.2016.1327.

[24] "bach 2019.pdf.".

[25] X. Cheng, Z. Huang, Z. Wang, C. Ma, dan S. Chen, "A novel on-site wheat straw pretreatment method: enclosed torrefaction," Bioresour. Technol., no. February, 2019, doi: 10.1016/j.biortech.2019.02.075.

[26] G. Talero, S. Rincón, dan A. Gómez, "Biomass torrefaction in a standard retort : A study on oil palm solid residues," Fuel, vol. 244, no. October 2018, hlm. 366-378, 2019, doi: 10.1016/j.fuel.2019.02.008.

[27] M. Manouchehrinejad dan S. Mani, "Energy Conversion and Management: X Process simulation of an integrated biomass torrefaction and pelletization ( iBTP) plant to produce solid biofuels," Energy Convers. Manag. X, vol. 1, no. April, hlm. 100008, 2019, doi: 10.1016/j.ecmx.2019.100008. 